\title{
The Effects of Abandonment Options on Investment Timing and Profit Sharing of FDI
}

\author{
Weiwei Zhang ${ }^{1,2}$ and Minggao Xue ${ }^{1}$ \\ ${ }^{1}$ School of Management, Huazhong University of Science \& Technology, 430074 Wuhan, China \\ ${ }^{2}$ Basic Teaching and Research Section, Wuhan Electronic Information Institute, 430019 Wuhan, China \\ Correspondence should be addressed to Weiwei Zhang; weiwei@hust.edu.cn
}

Received 13 June 2016; Accepted 11 January 2017; Published 9 April 2017

Academic Editor: Paolo Renna

Copyright ( 2017 Weiwei Zhang and Minggao Xue. This is an open access article distributed under the Creative Commons Attribution License, which permits unrestricted use, distribution, and reproduction in any medium, provided the original work is properly cited.

\begin{abstract}
The paper incorporates cooperative game theory into a real option method in a foreign direct investment setting and examines the operational decisions of a multinational corporation in a cooperative framework, where the corporation is endowed with an abandonment option and shares its profit with the host country. In particular, we investigate how the abandonment options affect the optimal investment timing and the optimal profit share of a foreign direct investment using a real option game method. We show that the flexibility of the abandonment option induces the corporation to investment earlier, which indicates the negative effects on investment trigger. The result is consistent with intuition since the abandonment option provides insurance and thus reduces the overall risk of the project. We also find that the introduction of the abandonment option reduces the optimal profit share in a cooperative framework and in turn the lower profit share increases the investment trigger, thereby having a positive effect on the investment threshold to hinder the investment. By numerical analysis, we find that the overall effect of the abandonment options is inversely related to the investment trigger. These findings provide quantitative analysis about the decisions regarding cooperation in international investment extraction projects.
\end{abstract}

\section{Introduction}

The globalization trend of foreign direct investment is increasingly strengthening and foreign direct investment has been experiencing rapid growth in recent years. According to the latest world investment report of the United Nations, the output value of multinational corporations and their parent companies accounts for nearly a quarter of global GDP [1-4]. In addition, a foreign direct investment involves large capital budgets, long construction periods, and high uncertainties, which include the fluctuation of international exchanges, the changes of product price, and the modification of national investment policy. When the investment encounters adverse conditions, then the divestment will occur [5-10].

Previous studies have extensively examined the investment timing decisions for foreign direct investment, thus providing decision-making information [11-21]. However, very few works consider the impacts of abandonment options on optimal investment decisions and profit sharing in cooperative games, especially in foreign direct investment. Moreover, it is common for multinational corporations (hereafter, MNC) to divest from the host country (hereafter, $\mathrm{HC}$ ) in light of the fiercely competitive environment and recent changes with regard to the MNC's strategies [6, 2224]. For instance, the withdrawal of Honda from Formula One in 2008 (Financial Times, 2008) reflects global financial distress and economic crisis in the auto industry. In addition, according to the data from the Ministry of Commerce of China, $4564 \mathrm{MNCs}$ left the host country market from January to November in 2008 (http://www.mofcom.gov.cn/). Consequently, it is critical to investigate the effect of abandonment options on the investment behaviors of MNCs in foreign direct investment, explore theoretic aspects concerning the economic significance of abandonment, and give quantitative analysis about the degree of impact, which in turn provides managerial insights and suggestions for $\mathrm{HC}$ to make foreign investment policies. 
In early research about the abandonment option, after the seminal work by Robichek and Van Horne [25], more and more literature has been concerned with abandonment options in capital budget and investment decisions. Myers and Majd [26] view the option to exit as an American put option with dividends, calculate the value of the abandonment option, and study the economic significance by using numerical analysis. McDonald and Siegel [27] examine a firm's investment decision, assuming that the firm can shut down production if variable costs exceed the net profits. Several papers investigate the abandonment decision on the natural resource investments. Based on the option pricing method, Brennan and Schwartz [28] evaluate the value of irreversible natural resources and provide suggestions on a coal mine's investment and abandonment decisions. Lain [29] examines the exit and expansion timing and indicates that it is optimal to delay investment or abandon the oil project when the prospects seemed to be bad and it is profitable to exercise the option to expand when the prospects are better. Further, from the perspective of corporate behavior and decisionmaking, Tsekrekos [30] studies a firm's optimal entry and exit decisions in the face of uncertainties about future profits and construction periods. Wong [31] investigates the behavior of a competitive firm when the firm has an abandonment option and has an access to a forward market under output price volatility. When the marginal cost is higher than the output price, it is optimal for the firm to exercise the option to exit and cease production. Wong [32] examines how the presence of an abandonment option affects a firm's investment decisions, especially the operating leverage. The results show that the firm will reduce operating leverage in the presence of an abandonment option, thereby making the firm more reluctant to invest in the project.

The purpose of the paper is to investigate the effects of abandonment options on investment timing and profit share in a cooperative game, combine real options with the bargaining game, and drive the investment timing of FDI and the optimal profit share between $\mathrm{HC}$ and MNC.

The most correlated literatures to our study are Brandão de Brito and de Mello Sampayo [19] and Di Corato [33], which also examine the investment decisions of a foreign direct investment in a real option framework. In Brandão de Brito and de Mello Sampayo [19], the firm's profit, which is determined by the attractiveness, follows a Brownian motion and the timing of foreign direct investment is delayed with the increase of uncertainty of attractiveness. Results from the model calibration support the model analysis. While Brandão de Brito and de Mello Sampayo [19] only provide an optimal rule for entry, the paper does not study the exit decisions of foreign direct investment. The work is also closely related to Di Corato [33], which only studies the investment decisions of MNC under the threat of nationalization and ignores the effects of an abandonment option on investment timing in cooperative games.

Our article incorporates cooperative game theory into the investment problem of foreign direct investment in a cooperative game using real options game model. In the model, MNC is endowed with the abandonment option after investment and cooperates with $\mathrm{HC}$ to extract natural resources and share the net project profit. During the investment process, MNC may be faced with the risk of asset expropriation by $\mathrm{HC}$ without any compensation and the loss of suck costs [33-36]. Therefore, MNC will divest at any time from $\mathrm{HC}$ if the project faces an adverse investment environment. The divestment decision of MNC from $\mathrm{HC}$ has a negative effect on employment and economic growth. Thus, HC should predict the investing behaviors of MNC with exit flexibility in cooperative game and further promote better cooperation with MNC by taking favorable policies. When MNC abandons the project, $\mathrm{HC}$ will pay for the salvage value of the project and take it over from MNC after the abandonment to promote national economic growth. Moreover, the option to completely or partially abandon a project has been widely used in practical application. For example, if the natural gas or oil price is volatile, producers will decide to expand or contract or even shut down production [28-30].

In particular, we explore the optimal investment timing of foreign direct investment with and without the abandonment option in real options game model, respectively, and investigate the effect of the abandonment options on investment trigger. We also examine the optimal profit share of $\mathrm{HC}$ and MNC by using Nash Bargaining Solutions in a cooperative framework in two cases and obtain main three interesting results.

The first one is that if the investment project is partially reversible, the optimal investment trigger of MNC with an abandonment option is smaller than that without. That is, the flexibility of the abandonment option induces the multinational corporation to investment earlier, which indicates the negative effects on investment trigger. So, MNC with an abandonment option has the incentive to invest in the project earlier than without. When MNC holds an option of abandonment and the project is completely irreversible, which indicates that the project has no salvage value, then two optimal investment thresholds in two cases are the same regardless of the abandonment option. The results show that the abandonment option pulls down the investment threshold.

The second is that the introduction of the abandonment option reduces the optimal profit share in a cooperative framework and in turn the lower profit share increases the investment trigger, thereby having a negative effect on the investment threshold if the multinational corporation is more risk averse. That is, the optimal profit share of MNC with the abandonment option is lower than that without, if the relative risk aversion is greater than some critical value. Moreover, the profit share is inversely related to the investment trigger. The results show that MNC with more risk aversion has considered the influences of the option to exit on the management flexibility, and $\mathrm{HC}$ gives up part of its profits from the project to induce MNC to invest in the absence of an abandonment option. Therefore, the optimal share is analytically determined in the bargaining process, depending on whether the project has an abandonment option or not.

Finally, we conclude that the two investment timing triggers decrease with the profit share and the abandonment option has two opposite effects on the investment in general, which is the positive effect, thereby pulling down 
the investment trigger and the other is the negative effect by increasing the critical investment value. By numerical analysis, we find that the overall effect of the abandonment options is inversely related to the investment trigger. The results indicate that the influences of the profit sharing ratio on the investment behavior dominate the influences of the abandonment options and MNC pays more attention to the profit sharing ratio.

The remainder of this paper is organized as follows. The model is presented in Section 2, and Section 3 derives the exit decision of MNC. Section 4 studies the investment decision of MNC in two cases: where the abandonment option is present or not in a cooperative framework. We also compare the investment trigger of MNC with the abandonment option of that without. We determine the optimal profit sharing ratio between MNC and $\mathrm{HC}$ and show that the optimal profit share without the abandonment option is always larger than that with it if the multinational corporation is more risk averse in Section 5. Section 6 conducts numerical analysis to access the solutions of the model and shows that the overall effect of the abandonment options is inversely related to the investment trigger. Finally, conclusions and topics for further research are presented in Section 7.

\section{The Model}

In the model, we assume that $\mathrm{MNC}$ and $\mathrm{HC}$ sign an agreement on engaging in the extraction of natural resources in the model. $\mathrm{HC}$ is finance-constrained and cannot pay for the total extraction cost of the project, while MNC can undertake investment cost $I$, where $I \geq 0$. Therefore, in order to encourage investment, promote economic growth, and improve the welfare of $\mathrm{HC}$, both parties make the following agreement on extraction of the natural resource: $\mathrm{HC}$ provides access to the extraction project and MNC undertakes the initial investment cost $I$ and extracts the natural resource in an infinite term. After completion of the project, both parties share each unit of profit, respectively, $\theta$ to MNC and $1-\theta$ to $\mathrm{HC}$, where $\theta \in(0,1)$. Due to the uncertainty of the national economic environment, market conditions, and the price of the extracted resource, $\mathrm{MNC}$ has the option of abandonment the project in the face of great price fluctuations.

When MNC decides to abandon the project, $\mathrm{HC}$ will pay the salvage value of the project $z I$ to MNC and take over the project, where $z \in[0,1]$ denotes the recovery rate of investment cost $I$. Similar to Wong [32], this indicates that the project is completely irreversible and has no salvage value if $z=0$. That is, MNC cannot get any profit when MNC shuts down the production. If $z=1$, the project is totally reversible, so that the salvage value of the project can recover investment cost. Consistent with the real context, MNC holds an option to invest in the extraction project and has an abandonment option when the profit flow is lower than a certain trigger in the model.

For the sake of simplicity, we assume that the operating cost, which is generally supposed to be constant in most models, is zero [32, 33, 37]. If the investment option is exercised at time $t, \mathrm{MNC}$ incurs the initial cost $I$, and the stochastic net profit flow per unit time of the project, $X_{t}$, is governed by the following geometric Brownian motion:

$$
d X_{t}=\mu X_{t} d t+\sigma X_{t} d z_{t}, \quad X_{0}=X
$$

where $\mu>0$ and $\sigma>0$ are the instantaneous drift and volatility and $z_{t}$ denotes the wiener process with $E\left(d z_{t}\right)=0$ and $E\left(d z_{t}^{2}\right)=d t$. We assume that MNC and HC are riskneutral and the risk-free rate is a constant $\rho$. For convergence, we also assume that $\rho>\mu$.

In order to investigate the effects of the abandonment option and profit share ratio on the investment timing of FDI, the model solves decision problems of MNC by using backward induction. First, as a bench mark, we derive the optimal exit and investment decisions of MNC without the option of abandonment. And, then, we compare the results to those in which MNC has the abandonment options. Finally, we determine the profit share ratio for both parties according to whether MNC possesses the option of abandonment or not.

\section{Optimal Exit Decisions from the Extractive Project}

In this section, we derive the postinvestment extractive project value before exercising the abandonment option and deduce the optimal exit decision by maximizing the profit of MNC.

After investment, MNC holds an option of abandonment. The abandonment option can be viewed as a perpetual American put option with an exercise price equal to the salvage value of project $z I$, and the underlying asset is the sequence profit flow of the project. After investment, the project produces net profit flow at time $t, X_{t}$. According to the agreement on the distribution of project profit, MNC acquires the net profit flow at time $t, \theta X_{t}$, and HC gets net profit flow at time $t,(1-\theta) X_{t}$.

Let $T_{e}=\inf \left\{\tau \geq t: X_{\tau}=X_{e}\right\}$ be the random first passage time for the state variable $X_{t}$ to reach $X_{e}$ from above. We refer to $X_{e}$ as the abandonment trigger, and the subscript $e$ denotes exit. That is, when the profit flow at time $t, X_{t}$, is lower than the abandonment trigger, $X_{e}, \mathrm{MNC}$ exercises the option to exit. The abandonment trigger, $X_{e}$, is endogenously determined by the model by maximizing the value of abandonment option.

So, prior to abandonment, the expected net present value of MNC after investment is given by

$$
S_{1}(X, \theta)=E\left[\int_{0}^{T_{e}} \theta X_{t} e^{-\rho t} d t+z I e^{-\rho T_{e}}\right] .
$$

Similarly, HC's expected net present value is

$$
\begin{aligned}
& G_{1}(X, \theta) \\
& =E\left[\int_{0}^{T_{e}}(1-\theta) X_{t} e^{-\rho t} d t+\int_{T_{e}}^{\infty} X_{t} e^{-\rho t} d t-z I e^{-\rho T_{e}}\right],
\end{aligned}
$$

where $E(\cdot)$ denotes the expected operator given that $X_{0}=X$. Equation (2) indicates that the expected net present value of 
the project for $\mathrm{MNC}$ is the profit share value of the project plus the salvage value of the project when MNC shuts down the production at the abandonment instant $T_{e}$. Equation (3) reveals that HC's expected net present value is equal to the profit share of the project plus the net present value of sequent profit flow, when the project is owned by HC.

Applying Ito's lemma, the value of active MNC, $S_{1}\left(X_{t}, \theta\right)$, satisfies the following ordinary differential equation (ODE):

$$
\frac{1}{2} \sigma^{2} X^{2} \frac{\partial^{2} S_{1}}{\partial X^{2}}+\mu X \frac{\partial S_{1}}{\partial X}-\rho S_{1}+\theta X=0
$$

Following the same procedure as Dixit and Pindyck [38] and Lucas and Prescott [39], the general solution of ODE (4) is given by

$$
S_{1}(X, \theta)=\frac{\theta X}{\rho-\mu}+A_{1} X^{\beta_{2}}, \quad X>X_{e}
$$

where $A_{1}$ is an endogenous constant and

$$
\beta=\frac{1}{2}-\frac{\mu}{\sigma^{2}} \pm \sqrt{\left(\frac{\mu}{\sigma^{2}}-\frac{1}{2}\right)^{2}+\frac{2 \rho}{\sigma^{2}}}, \quad \beta_{1}>1, \beta_{2}<0 .
$$

The constant $A_{1}$ and the abandonment trigger $X_{e}$ can be solely determined by the following value-matching and smooth-pasting conditions:

$$
\begin{aligned}
& S\left(X_{e}, \theta\right)=z I, \\
& S^{\prime}\left(X_{e}, \theta\right)=0 .
\end{aligned}
$$

Condition (7) expresses the fact that the perceived value of $\mathrm{MNC}$ at the abandonment instant $T_{e}$ is equal to the salvage value of the project $z I$. Condition (8) requires that the abandonment trigger $X_{e}$ should be chosen to maximize the perceived value of $\mathrm{MNC}$.

Under these conditions, $X_{e}$ and $A_{1}$ are solved as follows:

$$
\begin{aligned}
& X_{e}=\frac{\beta_{2}}{\beta_{2}-1} \frac{\rho-\mu}{\theta} z I, \\
& A_{1}=\left[z I-\frac{\theta X_{e}}{\rho-\mu}\right]\left(X_{e}\right)^{-\beta_{2}} .
\end{aligned}
$$

Note that the abandonment trigger $X_{e}$ decreases as the profit share $\theta$ increases. The result implies that the decrease in the abandonment threshold induces MNC to delay exiting the project.

Substituting (9) and (10) into (5) yields the value of MNC, $S_{1}\left(X_{t}, \theta\right)$, in the following form:

$$
\begin{aligned}
& S_{1}(X, \theta) \\
& = \begin{cases}\frac{\theta X}{\rho-\mu}+\left[z I-\theta\left(\frac{X_{e}}{\rho-\mu}\right)\right]\left(\frac{X}{X_{e}}\right)^{\beta_{2}} & \text { if } X>X_{e} \\
z I & \text { otherwise. }\end{cases}
\end{aligned}
$$

The first term of the first line of (11) represents the perpetual payment if MNC does not abandon the project, and the second term is the value of the abandonment option. On the second line, MNC gets the salvage value of project by exercising the option of abandonment.

Similarly, the value of $\mathrm{HC}, G_{1}(X, \theta)$, must satisfy the following ordinary differential equation:

$$
\frac{1}{2} \sigma^{2} X^{2} \frac{\partial^{2} G_{1}}{\partial X^{2}}+\mu X \frac{\partial G_{1}}{\partial X}-\rho G_{1}+(1-\theta) X=0 .
$$

The general solution to (12) is given by

$$
G_{1}(X, \theta)=(1-\theta)\left(\frac{X}{\rho-\mu}\right)+B_{1} X^{\beta_{2}}, \quad X>X_{e},
$$

where the constant $B_{1}$ can be solely determined by the boundary conditions.

HC gets the ownership of the extraction project while MNC is sold the salvage value of project $z I$ at the abandonment instant $T_{e}$. Therefore, the value of $\mathrm{HC}$ at the abandonment instant $T_{e}$ is

$$
G_{1}\left(X_{e}, \theta\right)=\frac{X_{e}}{\rho-\mu}-z I
$$

Combining with the above conditions, the value of $\mathrm{HC}$, $G_{1}(X, \theta)$, can be given by

$$
G_{1}(X, \theta)= \begin{cases}(1-\theta) \frac{X}{\rho-\mu}+B_{1} X^{\beta_{2}} & \text { if } X>X_{e} \\ \frac{X}{\rho-\mu}-z I & \text { otherwise. }\end{cases}
$$

According to the continuity condition, we obtain

$$
B_{1}=\frac{\theta X_{e}}{\rho-\mu}-z I
$$

Combining (15) with (16), we can get the explicit solution of $G_{1}(X, \theta)$.

\section{Optimal Investment Timing of the Extractive Project}

Next, the optimal investment decision is endogenously determined by the model. When the profit flow is sufficiently high or above a certain trigger, MNC will invest in the project immediately by incurring the initial investment cost. Therefore, we know that the optimal rule to exercise the option to invest is equivalent to finding a sufficiently high threshold $X_{i}$. It is optimal for MNC to exercise the option to invest when the state variable $X_{t}$ is the stochastic first passage time for the process from below. We refer to $X_{i}$ as the investment trigger. Let $T_{i}=\inf \left\{\tau \geq 0: X_{\tau}=X_{i}\right\}$ be the random first passage time for the state variable $X_{t}$ to reach $X_{e}$, from below. Next, we examine two different cases: the case without the abandonment option and the case with the option of abandonment. In what follows, we first outline the solutions for the two scenarios and then the results. 
4.1. Optimal Investment Decisions without the Option of Abandonment. As a benchmark, we first consider the investment decision in the absence of the abandonment option. When the abandonment option is prohibited, the profit distribution ratio of $\mathrm{MNC}$ is $\theta^{*}$ and $\mathrm{HC}$ 's profit share is $1-\theta^{*}$.

If abandonment is prohibited, MNC will perpetually run the extractive project. Therefore, when the project is undertaken, the expected net profit value of $\operatorname{MNC} F(X, \theta)$, can be represented as follows:

$$
F(X, \theta)=E\left[\int_{0}^{\infty} e^{-\rho t} \theta^{*} X_{t} d t \mid X_{0}=X\right]=\frac{\theta^{*} X}{\rho-\mu}
$$

$$
\left(X \geq X_{i}\right) \text {. }
$$

In the continuation region $X<X_{i}$, the ordinary differential equation for the value of $\operatorname{MNC~}_{2}\left(X, \theta^{*}\right)$ is given by

$$
\frac{1}{2} \sigma^{2} X^{2} \frac{\partial^{2} S_{2}}{\partial X^{2}}+\mu X \frac{\partial S_{2}}{\partial X}-\rho S_{2}=0 .
$$

The general solution of (18) can be expressed as

$$
S_{2}\left(X, \theta^{*}\right)=C_{1} X^{\beta_{1}} \text {. }
$$

According to the value-matching and smooth-pasting conditions

$$
\begin{aligned}
& S_{2}\left(X_{i}, \theta^{*}\right)=F\left(X_{i}, \theta^{*}\right)-I, \\
& S_{2}^{\prime}\left(X_{i}, \theta^{*}\right)=F^{\prime}\left(X_{i}, \theta^{*}\right) .
\end{aligned}
$$

We can solve the investment trigger $X_{i}^{*}$ and the constant $C_{1}$ in the following forms:

$$
\begin{aligned}
& X_{i}^{*}=\frac{\beta_{1}}{\beta_{1}-1} \frac{\rho-\mu}{\theta^{*}} I, \\
& C_{1}=\frac{\theta^{*}}{\beta_{1}(\rho-\mu)} X_{i}^{1-\beta_{1}} .
\end{aligned}
$$

Note that the optimal investment trigger $X_{i}^{*}$ of MNC without abandonment is negatively related to the distribution of profits $\theta^{*}$. We can see that the greater the profit share $\theta^{*}$ is, the smaller the investment trigger $X_{i}^{*}$ is, which indicates that MNC should invest earlier. As a result, to induce MNC to hasten investment, HC should increase the profit share $\theta^{*}$ to compensate for the investment loss of MNC in cases of lower profit flow.

To sum up, then, the value of MNC is expressed as

$$
S_{2}\left(X, \theta^{*}\right)= \begin{cases}\left(\frac{\theta^{*} X_{i}^{*}}{\rho-\mu}-I\right)\left(\frac{X}{X_{i}^{*}}\right)^{\beta_{1}} & \text { if } X<X_{i}^{*} \\ \frac{\theta^{*} X}{\rho-\mu}-I & \text { otherwise. }\end{cases}
$$

Accordingly, the value of $\mathrm{HC}$ can be expressed as

$$
\begin{aligned}
G_{2}\left(X, \theta^{*}\right) \\
= \begin{cases}{\left[\frac{\left(1-\theta^{*}\right) X_{i}^{*}}{\rho-\mu}\right]\left(\frac{X}{X_{i}^{*}}\right)^{\beta_{1}}} & \text { if } X<X_{i}^{*} \\
\frac{\left(1-\theta^{*}\right) X}{\rho-\mu}-I & \text { otherwise. }\end{cases}
\end{aligned}
$$

4.2. Optimal Investment Decisions with the Option of Abandonment. In this section, we assume that MNC holds an option of abandonment and possesses the profit share $\theta$ of the project as long as the firm invests in the extraction project. Therefore, MNC must decide when to invest at the presence of the abandonment option. We also assume that the net profit value of MNC is $S_{3}(X, \theta)$ and the abandonment trigger satisfies the inequality $X_{e}<X_{i}$; otherwise, no firm will invest in the project forever.

When the investment threshold satisfies the inequality $X \geq X_{i}>X_{e}$, the value of MNC at $X_{i}$ can be given by

$$
S_{1}\left(X_{i}, \theta\right)=\frac{\theta X_{i}}{\rho-\mu}+\left(z I-\theta \frac{X_{e}}{\rho-\mu}\right)\left(\frac{X_{i}}{X_{e}}\right)^{\beta_{2}},
$$

where the first term on the right-hand side of (25) is the profit value of MNC without the abandonment option, and the second term is the value of the option of abandonment at $X_{i}$.

The expression $z I-\theta\left(X_{e} /(\rho-\mu)\right)=\left(1 /\left(1-\beta_{2}\right)\right) z I>0$ shows the abandonment option is positive. If $X>X_{i}>X_{e}$, the profit value of $\mathrm{MNC}, S_{3}(X, \theta)$, can be expressed as

$$
S_{3}(X, \theta)=\frac{\theta X}{\rho-\mu}+\left(z I-\frac{\theta X_{e}}{\rho-\mu}\right)\left(\frac{X}{X_{e}}\right)^{\beta_{2}} .
$$

In the continuation region $X<X_{i}$, the profit value of $\mathrm{MNC}$ can be given by

$$
S_{3}(X, \theta)=C_{2} X^{\beta_{1}}
$$

According to the boundary conditions

$$
\begin{aligned}
& S_{3}\left(X_{i}, \theta\right)=S_{1}\left(X_{i}, \theta\right)-I, \\
& S_{3}^{\prime}\left(X_{i}, \theta\right)=S_{1}^{\prime}\left(X_{i}, \theta\right) .
\end{aligned}
$$

We solve implicitly the investment trigger, which satisfies the following equation:

$$
\begin{aligned}
& \left(1-\beta_{1}\right) \frac{\theta X_{i}}{\rho-\mu}+\left(\beta_{2}-\beta_{1}\right)\left(z I-\frac{\theta X_{e}}{\rho-\mu}\right)\left(\frac{X_{i}}{X_{e}}\right)^{\beta_{2}} \\
& +\beta_{1} I=0 .
\end{aligned}
$$

From (29), we see that MNC decides the investment timing to maximize the perceived net profit. Equation (30) is a nonlinear equation with no known analytical solution. Hence, the investment trigger can be obtained numerically. The result in (30) demonstrates that the investment trigger $X_{i}$ depends on the profit share $\theta$, the abandonment threshold $X_{e}$, and the recovery rate $z$.

To sum up, we rewrite the value of MNC:

$$
\begin{aligned}
& S_{3}(X, \theta) \\
& = \begin{cases}{\left[\frac{\theta X_{\mathrm{i}}}{\rho-\mu}+\frac{z I}{1-\beta_{2}}\left(\frac{X_{i}}{X_{e}}\right)^{\beta_{2}}-I\right]\left(\frac{X}{X_{i}}\right)^{\beta_{1}}} & \text { if } X \leq X_{i} \\
\frac{\theta X}{\rho-\mu}+\frac{1}{1-\beta_{2}} z I\left(\frac{X_{i}}{X_{e}}\right)^{\beta_{2}}-I & \text { otherwise. }\end{cases}
\end{aligned}
$$


Similarly, the perceived profit value of $\operatorname{HC~}_{3}(X, \theta)$ at $X>X_{i}$ can be expressed as

$$
G_{3}(X, \theta)=\frac{(1-\theta) X}{\rho-\mu}+\left(\frac{\theta X_{e}}{\rho-\mu}-z I\right)\left(\frac{X}{X_{e}}\right)^{\beta_{2}} .
$$

Therefore, the value of $\mathrm{HC}$ is given by

$$
\begin{aligned}
& G_{3}(X, \theta) \\
& = \begin{cases}{\left[\frac{(1-\theta) X_{i}}{\rho-\mu}-\frac{z I}{1-\beta_{2}}\left(\frac{X_{i}}{X_{e}}\right)^{\beta_{2}}\right]\left(\frac{X}{X_{i}}\right)^{\beta_{1}}} & \text { if } X \leq X_{i} \\
\frac{(1-\theta) X}{\rho-\mu}-\frac{1}{1-\beta_{2}} z I\left(\frac{X_{i}}{X_{e}}\right)^{\beta_{2}} & \text { otherwise. }\end{cases}
\end{aligned}
$$

\subsection{Comparative Analysis about Two Investments Triggers in} Two Cases

Proposition 1. (a) When abandonment is prohibited, the investment trigger can be given by $X_{i}^{*}=\left(\beta_{1} /\left(\beta_{1}-1\right)\right)((\rho-$ $\left.\mu) / \theta^{*}\right) I$. (b) When MNC holds the option of abandonment and the project is partially reversible (i.e., $0<z \leq 1$ ), the optimal investment trigger of MNC is always greater without the abandonment option than with it; that is, $X_{i}^{*}>X_{i}$. And if the project is irreversible $(z=0)$, the two investment thresholds are the same, $X_{i}=X_{i}^{*}$.

Proposition 1 shows that MNC hastens to invest in the extraction project at the presence of abandonment option and the abandonment option produces the acceleration effect for investment. That is, the abandonment option provides downside protection for $\mathrm{MNC}$ and has a negative effect that pulls down the investment trigger. Therefore, MNC with the option of abandonment has greater flexibility and encourages MNC to invest earlier for more profits. In the cooperative extraction project with uncertainty and irreversibility, the acceleration effect makes foreign direct investment contribute to economic growth of $\mathrm{HC}$, which is consistent with Borensztein et al. [40]. To attract a foreign direct investment and have a positive effect on overall economic growth of HC, HC should adopt many policy measures and provide the MNC with more managerial flexibility to induce more investment.

Proposition 2. Irrespectively of whether MNC is endowed with the abandonment option or not, the optimal investment timing is negative with the profit share.

The intuition of Proposition 2 is as follows. As the profit share goes up, the investment trigger goes down and the presence of the abandonment options has no influence on the relationship between the investment trigger and profit share. As such, the investment trigger is inversely related to the profit share.

\section{Nash Bargaining Game about the Optimal Profit Sharing}

The determination of profit share can be solved by Nash bargaining game. The bargaining process is carried out between
MNC and HC. We derive the solution about the optimal profit share by the Nash Bargaining Solution, which is created by Harsanyi [41, 42] and Rubinstein (1987). Both players must find an explicit agreement on profit distribution before project runs. So we can view this situation as a cooperative game and derive a Nash Bargaining Solution (NBS), which can be solved by maximizing the joint profit of both players.

Both players share the same information about future profit $X_{t}$ for extractive project and are adverse to internal conflicts before the project runs. They must reach an agreement about the profit distribution by maximizing the joint objective function $\nabla_{1}$. Because of the uncertainties of future profit flow and the market volatility, both players, respectively, determine the profit share, according to being with or without the abandonment option. It is assumed that the profit share of $\mathrm{MNC}$ is $\theta^{*}$ and $\theta$, respectively, according to MNC without and with the option of abandonment.

As in Moretto and Rossini [43, 44], the joint objective profit function $\nabla_{1}$ of both players can be expressed as $\nabla_{1}=$ $\ln \left[U\left(S_{i}\right)-\stackrel{\Lambda}{U}\right]+\ln \left[V\left(G_{i}\right)-\stackrel{\Lambda}{V}\right](i=2,3)$, where $U(S)$ and $V(G)$, respectively, are defined as the utility function of MNC and HC and $\stackrel{\Lambda}{U}$ and $\stackrel{\Lambda}{V}$ are disagreement payoffs. For both players, if the bargaining fails, they will not invest in the project and possess zero utility. So, it is assumed that $\stackrel{\Lambda}{U} \stackrel{\Lambda}{V}=0$. Because the determination of profit sharing is prior to investment, the profit flow satisfies $X<X_{e}<X_{i}$ or $X<X_{i}^{*}$. In addition, as in Moretto and Rossini [43], it is assumed that $U\left(S_{i}\right)=S_{i}{ }^{1-R}$ and $V\left(G_{i}\right)=G_{i}{ }^{q}(0<R<1,0<q<1)$, where they, respectively, represent the Von-Neumann-Morgenstern utility of $\mathrm{MNC}$ and $\mathrm{HC}$ and $1-R$ and $q$ denote the degrees of relative risk aversion of both players, respectively.

Both players play cooperative game at $X_{i}$ or $X_{i}{ }^{*}$ and determine the optimal profit share $\theta^{*}$ or $\theta$ by maximizing the joint objective utility function. Then, cooperative objective function for determining the optimal profit share can be given by

$$
\max _{\theta} \quad \nabla_{1}=\ln \left(S_{i}^{1-R}\right)+\ln \left(G_{i}^{q}\right) \quad(i=2,3) .
$$

Differentiating (34) with respect to $\theta$, we get

$$
\frac{G_{i}}{S_{i}} \cdot \frac{\partial S_{i} / \partial \theta}{\partial G_{i} / \partial \theta}=-\eta
$$

where $\eta=q /(1-R)$.

5.1. Optimal Profit Share $\theta^{*}$ in the Absence of the Abandonment Option

Proposition 3. When the abandonment option is absent, the optimal profit share, $\theta^{*}$, can be given by

$$
\theta^{*}=1-\frac{\eta}{\beta_{1}+\eta} .
$$

The result is consistent with Di Corato [33]. However, Di Corato [33] focuses on the outcome of profit sharing under the threat of nationalization, which is different from 
the model setting. From (36), the optimal profit share $\theta^{*}$ is related to the relative risk aversion ratio $\eta$. We get $\partial \theta^{*} / \partial \eta<0$, all other things being equal. It indicates that the greater the relative risk aversion ratio $\eta$, the smaller the optimal share, which implies that MNC must compensate for $\mathrm{HC}$ with more risk aversion with a higher profit share.

5.2. Optimal Profit Share $\theta^{*}$ at the Presence of the Abandonment Option. For given $X_{i}$, substituting (31) and (33) into (35), maximizing (35) at $X_{i}$ and differentiating (36) with respect to $\theta$, we can get

$$
\theta=\frac{\beta_{1}-\beta_{2}}{\left(1-\beta_{2}\right)(1+\eta)}-\frac{\beta_{1} I(\rho-\mu)}{\left(1-\beta_{2}\right) X_{i}} .
$$

Equation (37) indicates that the optimal profit share $\theta$ is related to the volatility $\sigma$, the relative risk aversion ratio $\eta$, the interest rate $\rho$, and the recovery rate and the expression explicitly includes investment threshold $X_{i}$. Therefore, in order to identify both optimal trigger and optimal profit share (i.e., $X_{i}$ and $\theta$ ), (30) and (37) must be solved simultaneously.

Proposition 4. If the relative risk aversion ratio $\eta>-\beta_{1} / \beta_{2}$, the optimal profit share $\theta$ with the option of abandonment is always smaller than that without $\theta^{*}$; that is, $\theta<\theta^{*}$.

Proposition 4 shows that introducing the abandonment option induces MNC to lower its optimal profit share, thereby making MNC more reluctant to invest in the extraction program. It surprisingly uncovers that a risk-averse MNC with the abandonment option has a lower profit share. Moreover, Proposition 2 shows that the profit sharing ratio is negative with the investment trigger, which indicates that the more the profit sharing, the earlier to investment the project under the two cases. According to Proposition 4, MNC with risk aversion will lead to investing later in extraction program and is consistent with Proposition 2 and will ask for more profit sharing to induce the investment. It reflects that the attitude to the risk of investment will influence the profit sharing and further the investment timing. Hence, the abandonment option has negative effect on the investment.

Proposition 5. The abandonment option has two opposite effects on the optimal investment trigger.

Proposition 1 captures the positive effect of the abandonment option on the investment. And the flexibility to abandon the project provides the downside risk for MNC, therefore inducing MNC to invest earlier, which pulls down the investment trigger. On the other hand, the combination of Propositions 2 and 4 shows the abandonment option has a negative effect on the extractive investment, which lifts up the investment trigger. Hence, the effect of the abandonment option on investment has an ambiguous impact.

\section{Results}

In this part, we first analyze some properties of profit shares $\theta^{*}$ and $\theta$ in the cooperative game and then discuss the impact

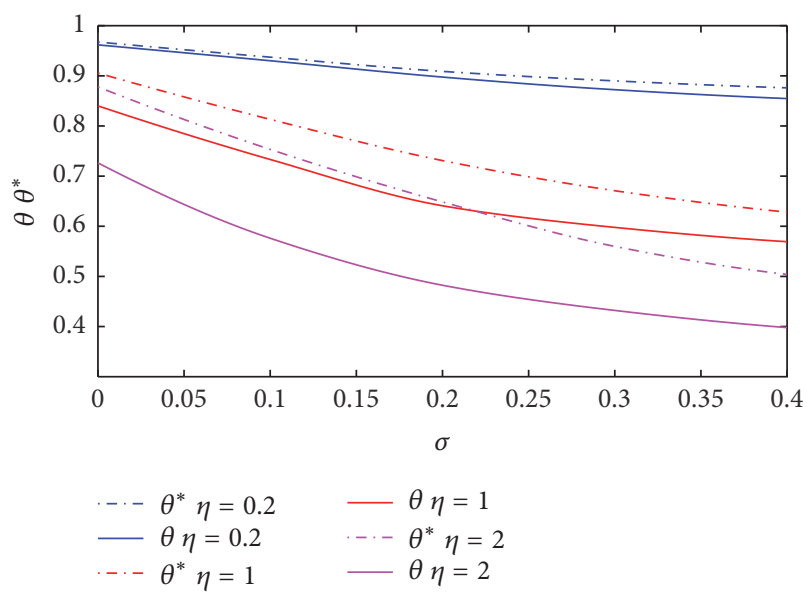

Figure 1: Dependence of $\theta^{*}$ and $\theta$ on $\sigma$.

of market volatility, $\sigma$, the expected growth rate, $\mu$, and the relative degree of risk aversion, $\eta$, on the optimal profit shares $\theta$ and $\theta^{*}$ under two scenarios. Next, the analysis and comparison of two investment thresholds $X_{i}^{*}$ and $X_{i}$ will be obtained. Similarly to Di Corato [33] and Wong [32], we use the parameter values as follows: $\mu=0.01, \sigma=0.3, \rho=0.05$, $z=0.5, I=1$, and $\eta=0.2$.

\subsection{Relationship of Profit Shares $\theta$ and $\theta^{*}$ in Two Cases}

6.1.1. On the Impact of Volatility $\sigma$. According to (30), (36), and (37), Figure 1 plots the optimal profit shares $\theta^{*}$ and $\theta$ with the volatility $\sigma$ at different relative risk aversion ratio $\eta$. From Figure 1, it can be shown that both profit shares $\theta^{*}$ and $\theta$ accordingly decrease as volatility $\sigma$ increases. When the relative risk aversion ratio $\eta$ increases and $\sigma$ is near $10 \%$, $\mathrm{HC}$ is more risk averse than MNC. In order to make the two players reach an agreement to run the project together, less risk-averse MNC gets a lower share of the profits and makes risk-averse $\mathrm{HC}$ large gains, which accordingly makes the difference between the two investment thresholds larger and larger. When the volatility $\sigma$ increases over $10 \%$, there will be the opposite. Therefore, the actual determined profit share ratio should be based on the degree of risk aversion and uncertainties in cooperative project.

6.1.2. On the Impact of Expected Growth Rate $\mu$. As seen in Figure 2, an increase in the expected growth rate, $\mu$, lowers the optimal profit shares $\theta^{*}$ and $\theta$. These show that when the market environment becomes better, the potential future earnings are relatively high, and $\mathrm{MNC}$ will give up an additional portion of the profit share to induce cooperation with HC. Observe from Figures 1 and 2 that no matter how the parameter values change, the optimal profit share with the exit option $\theta$ is always less than $\theta^{*}$ without and the greater the relative risk ratio is, the more sharply the graph decreases, which indicates that the impact of the risk attitude of MNC on the optimal profit share dominates that of the expected growth rate. Therefore, $\mathrm{HC}$ should firstly consider the risk 


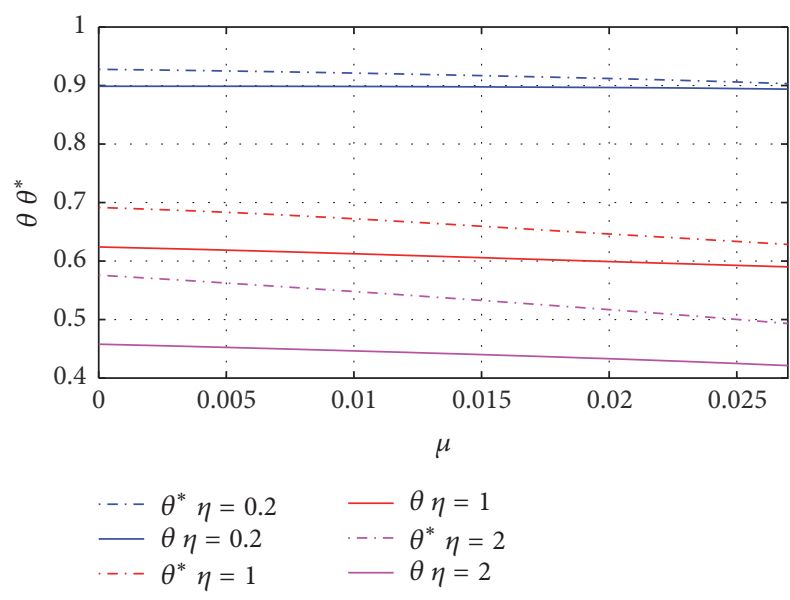

Figure 2: Dependence of $\theta^{*}$ and $\theta$ on $\mu$.

appetite of MNC in the bargaining process to determine the optimal share of profits in cooperative framework.

6.2. The Analysis of Investment Thresholds. In this section, we discuss how the investment thresholds change with the profit share $\theta$, the volatility $\sigma$, and the expected growth rate $\mu$ under two scenarios.

6.2.1. Effect of Share of Profits on the Investment Thresholds. Figure 3 has shown the relationship between investment thresholds and profit shares $\theta$. With the base case parameter values, the solutions to (9), (21), (30), (36), and (37) are as follows: optimal exit trigger $X_{e}=0.0097$, optimal investment trigger with the abandonment options $X_{i}=$ 0.1266 , optimal investment trigger without the abandonment options $X_{i}^{*}=0.1327$, optimal profit share under no exit options $\theta^{*}=0.8898$, and optimal profit share with the option of abandonment $\theta=0.8722$. To further understand the difference of the two investment triggers, we suppose the initial value of the variable, $X_{t}$, is 0.1266 , since the investment timing with the abandonment option is 0.1266 . As discussed in Sarkar [45], the expected time for the variable $X_{t}$ from $X_{i}$ to $X_{i}^{*}$ is infinite by calculating and the arrival probability is 95.84\% with the use of the expression: $\left(X_{i}^{*} / X_{i}\right)^{\left[\left(2 \mu / \sigma^{2}\right)-1\right]}$. That is, once the abandonment options are accounted for, MNC will be hastened to invest in the project with the accelerated effect. In contrast, MNC without the abandonment options will delay a longer time by numerical analysis. Thus, the effect of the abandonment option on the optimal investment timing is economically significant.

In addition, Figure 3 shows the threshold is reduced with share $\theta$ under two scenarios. The abandonment option has two opposite effects on the investment in general, one is the positive effect, thereby pulling down the investment trigger, and the other is the negative effect by increasing the critical investment value. We identify that the overall effect of the abandonment options is inversely related to the investment trigger through Figure 3.
6.2.2. Relationship between Volatility and Investment Thresholds. Figure 4 has shown the impacts of volatility $\sigma$ and risk aversion $\eta$ on $X_{i}^{*}$ and $X_{i}$. From the graph, the investment threshold with the option of abandonment is always larger than that without, which is in line with Proposition 1. And the investment threshold is positively related to the volatility. The relationship of the change rate and the relative degree of risk aversion $\eta$ are determined in the curve. When $\eta$ is comparatively small $(\eta=0.2)$, the little change of investment threshold is shown. Meanwhile, the gap of two investment triggers is becoming wider and wider with the increasing of $\eta$. All these show that the relative degree of risk aversion plays an important role in the investment decision and MNC with more risk aversion increases investment threshold and postpones investment, while the profit sharing of MNC at this time is also reduced by combining Figure 1 with Figure 3. And we see that as the relative risk aversion ratio $\eta$ increases, the reduction of profit shares will enlarge investment threshold.

6.2.3. Relationship between Expected Growth Rate and Investment Threshold at Different Risk Aversion Ratio. Figure 5 shows the relationships between the growth rate $\mu$ and two investment thresholds. When $\eta$ is very small $(\eta=0.2)$, along with the increasing of $\mu$, that is, $\partial X_{i}^{*} / \partial \mu<0$ and $\partial X_{i}^{*} / \partial \mu<0$, the investment triggers will reduce. The change rate of $X_{i}^{*}$ to $\mu$ will be larger than the change rate of $X_{i}$ to $\mu$, making the curve descend. However, when $\eta$ increases to over 1, two investment thresholds will increase. This shows that when $\mathrm{HC}$ is increasingly risk averse, the profit sharing will get smaller and smaller with the expected growth rate of the project. Since profit sharing has a negative effect on investment thresholds, MNC will postpone investment with profit sharing decreases. At this point, the negative effect of profit sharing on investment thresholds dominates that of the growth rate; hence, the curve of investment thresholds shows an increasing trend, making MNC delay the investment.

\section{Conclusions}

In this paper, we examine the investment timing of foreign direct investment and the optimal profit share between HC and MNC with an option of abandonment in a cooperative framework. Combining the real options with bargaining game, the results show that when the project is partially reversible in the presence of abandonment option, the investment threshold of FDI is always less than that under no exit option and the abandonment option has a negative impact on the investment trigger. When the project is completely irreversible, the investment timing in both cases remains the same. In addition, we demonstrate the relationship between the profit shares without an exit option $\theta^{*}$ and $\theta$ when there is an exit option. From the study, it can be shown that if the relative risk aversion ratio is greater than some critical value, $\theta^{*}$ is always larger than $\theta$, which shows the introduction of the abandonment options has a positive effect on investment trigger since the profit share is inversely related to the investment trigger. Using the numerical analysis, we verify the total effect of the abandonment option is negative. 


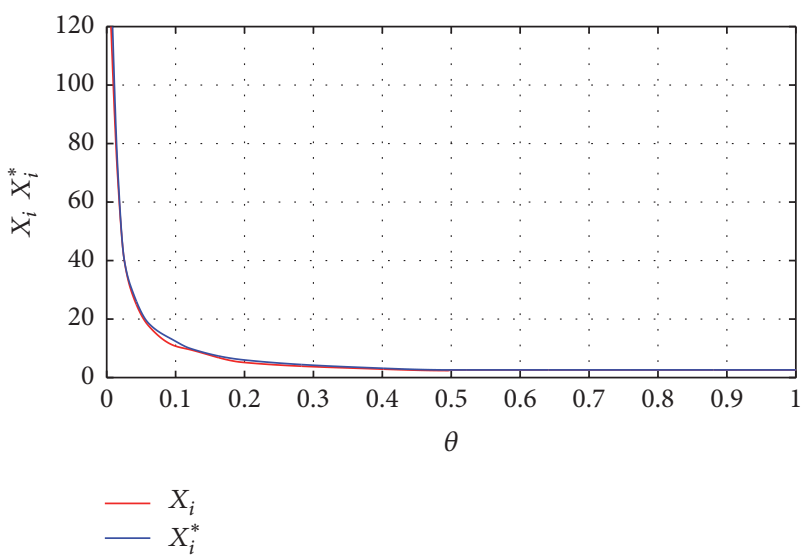

(a)

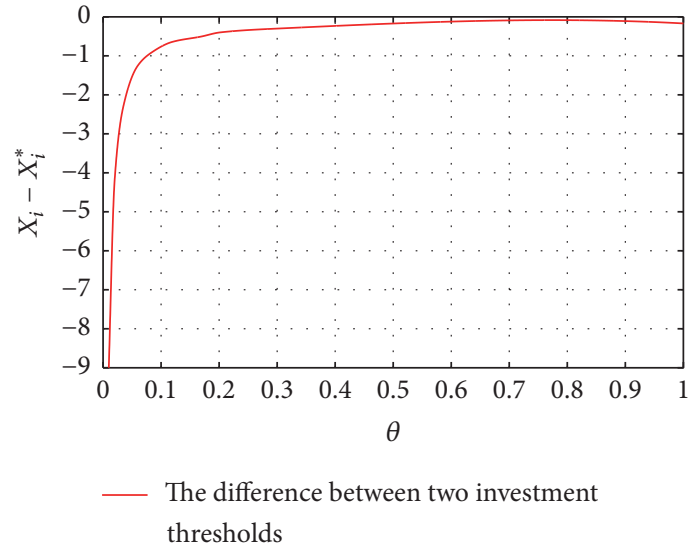

(b)

Figure 3: (a) Effect of profit shares on investment triggers. (b) Effect of profit shares on the difference.

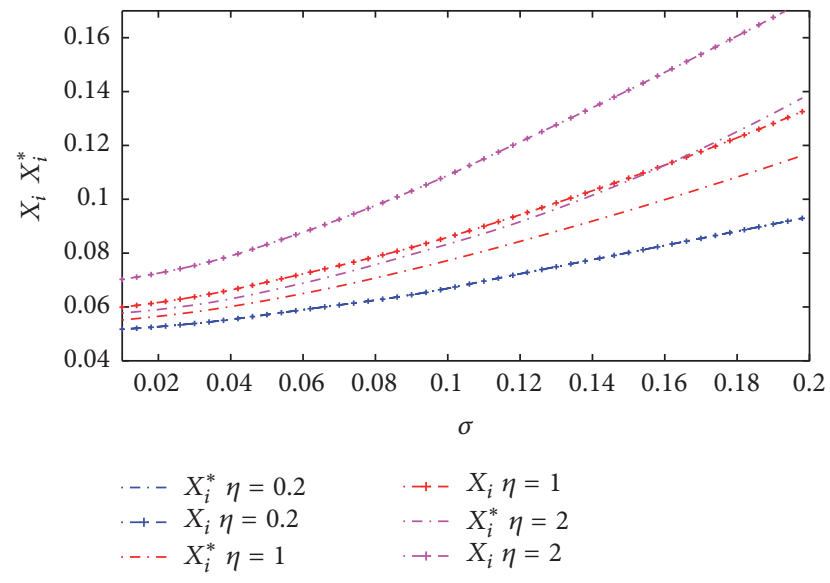

FIGURE 4: Investment triggers change with volatility.

MNC with management flexibility will be more eager to invest in the project.

Although this paper draws some practical conclusions, it did not consider the impacts of the political risk on the investment of MNC. If we incorporate the change of tax rate or nationalization into the model, the relationship of the investment timing and the profit sharing under political risk will be further studied. This is the future direction of study.

\section{Appendix}

\section{A. Proof of Proposition 1}

(1) According to (21), we can get Proposition 1(a).

(2) We rewrite (30) as

$$
\begin{aligned}
& \left(1-\beta_{1}\right) \frac{\theta X_{i}}{\rho-\mu}+\beta_{1} I \\
& \quad=\left(\beta_{1}-\beta_{2}\right)\left(z I-\theta \frac{X_{e}}{\rho-\mu}\right)\left(\frac{X_{i}}{X_{e}}\right)^{\beta_{2}} .
\end{aligned}
$$

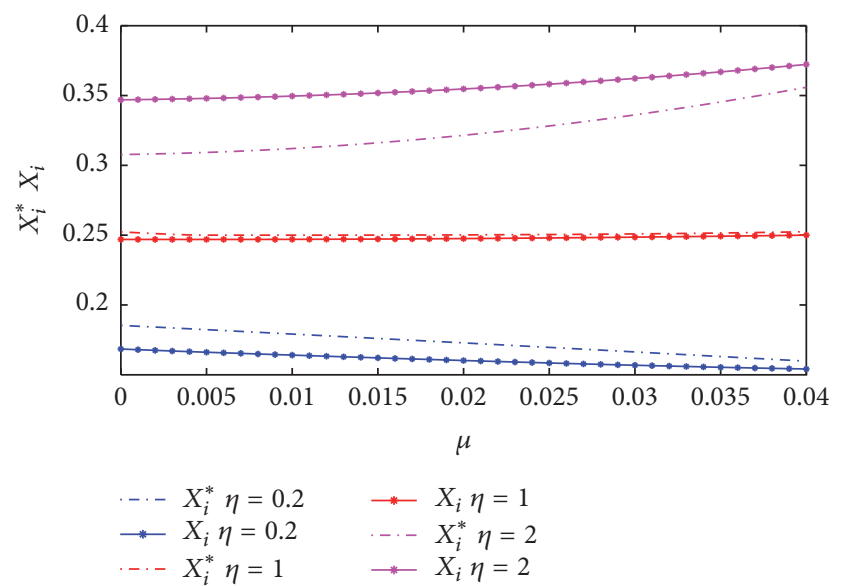

FIGURE 5: Relationships between expected growth rate and investment thresholds.

The expressions $z I-\theta\left(X_{e} /(\rho-\mu)\right)=\left(1 /\left(1-\beta_{2}\right)\right) z I \geq 0$ and $\beta_{1}>\beta_{2}$ hold, and we can get $\left(1-\beta_{1}\right)\left(\theta X_{i} /(\rho-\mu)\right)+\beta_{1} I \geq 0$. That is, $X_{i} \leq X_{i}^{*}$. If the project is partially reversible $(0<z \leq$ 1 ), we have $X_{i}^{*}>X_{i}$ or else $X_{i}=X_{i}^{*}$.

\section{B. Proof of Proposition 2}

Differentiating $X_{i}$ and $X_{i}^{*}$ in (30) and (21) with respect to $\theta$ and $\theta^{*}$ yields

$$
\begin{aligned}
& \frac{\partial X_{i}^{*}}{\partial \theta^{*}}=-\frac{X_{i}^{*}}{\theta}<0 \\
& {\left[\frac{\left(1-\beta_{1}\right) \theta}{\rho-\mu}+\frac{\beta_{2}-\beta_{1}}{1-\beta_{2}} \beta_{2} \cdot z I\left(\frac{X_{i}^{\beta_{2}-1}}{X_{e}^{\beta_{2}}}\right)\right] \frac{\partial X_{i}}{\partial \theta}} \\
& \quad=\left(\beta_{1}-1\right) \frac{X_{i}}{\rho-\mu}-\frac{\left(\beta_{2}-\beta_{1}\right) \beta_{2}}{\left(1-\beta_{2}\right) \theta}\left(\frac{X_{i}}{X_{e}}\right)^{\beta_{2}} .
\end{aligned}
$$


Rearranging the above equation, we get

$$
\frac{\partial X_{i}}{\partial \theta}=-\frac{X_{i}}{\theta}<0
$$

\section{Proof of Proposition 3}

Substituting (23) and (24) into (35), we can get (36).

\section{Proof of Proposition 4}

Calculating the following expression: $\theta^{*}-\left(\beta_{1}-\beta_{2}\right) /\left(1-\beta_{2}\right)(1+$ $\eta)$, we can get $\left(1-\beta_{1}\right)\left(\beta_{2} \eta+\beta_{1}\right) /\left(1-\beta_{2}\right)\left(\beta_{1}+\eta\right)(1+\eta)$. Since $\beta_{1}>1, \beta_{2}<0$, and $\eta>0$, it follows that $\theta^{*}>\left(\beta_{1}-\beta_{2}\right) /(1-$ $\left.\beta_{2}\right)(1+\eta)$ if $\eta>\beta_{1} /\left(1-\beta_{2}\right)$. Note that $\rho>\mu$, and then if $\eta>-\beta_{1} / \beta_{2}$ and $\eta>\beta_{1} /\left(1-\beta_{2}\right)$, the inequality $\theta<\theta^{*}$ holds.

\section{Disclosure}

Needless to say, the authors are responsible for any detected errors.

\section{Conflicts of Interest}

The authors declare that they have no conflicts of interest.

\section{Acknowledgments}

The authors thank seminar participants at Department of Finance, School of Management, Huazhong University of Science of Technology. Finally, the authors acknowledge the financial support from Natural Science Foundation of China (no. 70871046, no. 71171091, and no. 71471070).

\section{References}

[1] J.-C. Berthélemy and S. Démurger, "Foreign direct investment and economic growth: theory and application to China," Review of Development Economics, vol. 4, no. 2, pp. 140-155, 2000.

[2] S. Yao and K. Wei, "Economic growth in the presence of FDI: the perspective of newly industrialising economies," Journal of Comparative Economics, vol. 35, no. 1, pp. 211-234, 2007.

[3] C. Zhong, "Empirical evidence on the regional spillover effects of FDI in China," Economic Research Journal, vol. 1, pp. 80-89, 2010 (Chinese).

[4] K. Liu, Y. Cao, Y. Mou, and X. Sun, "Regional policy change and multinational corporations' space layout evolution in the Yangtze River Delta," Progress in Geography, vol. 32, no. 5, pp. 797-806, 2013.

[5] J. J. Boddewyn, "Foreign divestment: magnitude and factors," Journal of International Business Studies, vol. 10, no. 1, pp. 21-26, 1979.

[6] J. Li, "Foreign entry and survival: effects of strategic choices on performance in international markets," Strategic Management Journal, vol. 16, no. 5, pp. 333-351, 1995.

[7] N. Pain and G. Young, "The macroeconomic impact of UK withdrawal from the EU," Economic Modelling, vol. 21, no. 3, pp. 387-408, 2004.
[8] L. Xu, "Divestment of MNCs in China and its countermeasures under financial crisis," Contemporary Finance \& Economics, vol. 12, article 016, 2009.

[9] S. Song, "Unfavorable market conditions, institutional and financial development, and exits of foreign subsidiaries," Journal of International Management, vol. 20, no. 3, pp. 279-289, 2014.

[10] M. Ebell, I. Hurst, and J. Warren, "Modelling the long-run economic impact of leaving the European Union," Economic Modelling, vol. 59, pp. 196-209, 2016.

[11] P. J. Buckley and M. Casson, "The optimal timing of a foreign direct investment," The Economic Journal, vol. 91, no. 361, pp. 75-87, 1981.

[12] B. Kogut and N. Kulatilaka, "Operating flexibility, global manufacturing, and the option value of a multinational network," Management Science, vol. 40, no. 1, pp. 123-139, 1994.

[13] P. Rivoli and E. Salorio, "Foreign direct investment and investment under uncertainty," Journal of International Business Studies, vol. 27, no. 2, pp. 335-357, 1996.

[14] A. Buckley, "International capital budgeting, real operating options and FDI," Managerial Finance, vol. 22, no. 1, pp. 19-40, 1996.

[15] K. Saggi, "Optimal timing of foreign direct investment under uncertainty," Journal of Transnational Management Development, vol. 3, no. 2, pp. 73-87, 1998.

[16] S. J. Chang and H. Singh, "The impact of modes of entry and resource fit on modes of exit by multibusiness firms," Strategic Management Journal, vol. 20, no. 11, pp. 1019-1035, 1999.

[17] J. Darby, A. H. Hallett, J. Ireland, and L. Piscitelli, “The impact of exchange rate uncertainty on the level of investment," The Economic Journal, vol. 109, no. 454, pp. C55-C67, 1999.

[18] H. Sung and H. E. Lapan, "Strategic foreign direct investment and exchange-rate uncertainty," International Economic Review, vol. 41, no. 2, pp. 411-423, 2000.

[19] J. Brandão de Brito and F. de Mello Sampayo, "The timing and probability of FDI: an application to US multinational enterprises," Applied Economics, vol. 37, no. 4, pp. 417-435, 2005.

[20] B. M. Gilroy and E. Lukas, "The choice between greenfield investment and cross-border acquisition: a real option approach," Quarterly Review of Economics \& Finance, vol. 46, no. 3, pp. 447-465, 2006.

[21] C.-F. Yu, T.-C. Chang, and C.-P. Fan, "FDI timing: entry cost subsidy versus tax rate reduction," Economic Modelling, vol. 24, no. 2, pp. 262-271, 2007.

[22] P. K. Jagersma and D. M. van Gorp, "International divestments-an empirical perspective," Business Horizons, vol. 46, no. 6, pp. 61-69, 2003.

[23] D. Greenaway and R. Kneller, "Firm heterogeneity, exporting and foreign direct investment," The Economic Journal, vol. 117, no. 517, pp. F134-F161, 2007.

[24] A. Hryckiewicz and O. Kowalewski, "Why do foreign banks withdraw from other countries?" International Finance, vol. 14, no. 1, pp. 67-102, 2011.

[25] A. A. Robichek and J. C. Van Horne, "Abandonment value and capital budgeting," The Journal of Finance, vol. 22, no. 4, pp. 577589,1967

[26] S. C. Myers and S. Majd, "Calculating abandonment value using option pricing theory," Working Paper, Alfred P. Sloan School of Management, MIT, Cambridge, Mass, USA, 1984.

[27] R. L. McDonald and D. R. Siegel, "Investment and the valuation of firms when there is an option to shut down," International Economic Review, vol. 26, no. 2, pp. 331-349, 1985. 
[28] M. J. Brennan and E. S. Schwartz, "Evaluating natural resource investments," The Journal of Business, vol. 58, no. 2, pp. 135-157, 1985.

[29] J. P. Lain, "Optimal valuation of field development projects," in Proceedings of the SPE Hydrocarbon Economics and Evaluation Symposium, SPE37965, Dallas, Tex, USA, 1997.

[30] A. E. Tsekrekos, "Investment under economic and implementation uncertainty," R\& D Management, vol. 31, no. 2, pp. 127-135, 2001.

[31] K. P. Wong, "The effects of abandonment options on operating leverage and forward hedging," International Review of Economics and Finance, vol. 15, no. 1, pp. 72-86, 2006.

[32] K. P. Wong, "The effects of abandonment options on operating leverage and investment timing," International Review of Economics and Finance, vol. 18, no. 1, pp. 162-171, 2009.

[33] L. Di Corato, "Profit sharing under the threat of nationalization," Resource and Energy Economics, vol. 35, no. 3, pp. 295-315, 2013.

[34] N. V. Long, "Resource extraction under the uncertainty about possible nationalization," Journal of Economic Theory, vol. 10, no. 1, pp. 42-53, 1975.

[35] E. Clark, "Pricing the cost of expropriation risk," Review of International Economics, vol. 11, no. 2, pp. 412-422, 2003.

[36] A. B. Trolle and E. S. Schwartz, Pricing Expropriation Risk in Natural Resource Contracts: A Real Options Approach, MIT Press, Cambridge, Mass, USA, 2008.

[37] E. Lyandres and A. Zhdanov, "Accelerated investment effect of risky debt," Journal of Banking and Finance, vol. 34, no. 11, pp. 2587-2599, 2010.

[38] A. K. Dixit and R. S. Pindyck, Investment Under Uncertainty, Princeton University Press, Princeton, NJ, USA, 1994.

[39] J. Lucas and E. C. Prescott, "Investment under uncertainty," Econometrica, vol. 39, pp. 659-681, 1971.

[40] E. Borensztein, J. De Gregorio, and J.-W. Lee, "How does foreign direct investment affect economic growth?" Journal of International Economics, vol. 45, no. 1, pp. 115-135, 1998.

[41] J. C. Harsanyi, "Approaches to the bargaining problem before and after the theory of games. A critical discussion of Zeuthen's, Hicks', and Nash's theories," Econometrica, vol. 24, pp. 144-157, 1956.

[42] J. C. Harsanyi, Rational Behavior and Bargaining Equilibrium in Games and Social Situations, Cambridge University Press, Cambridge, UK, 1988.

[43] M. Moretto and G. Rossini, "The shut-down option and profit sharing," Journal of Comparative Economics, vol. 21, no. 2, pp. 154-186, 1995.

[44] M. Moretto and G. Rossini, "Profit sharing regulation and repeated bargaining with a shut-down option," Economic Design, vol. 2, no. 1, pp. 339-368, 1996.

[45] S. Sarkar, "Optimal size, optimal timing and optimal financing of an investment," Journal of Macroeconomics, vol. 33, no. 4, pp. 681-689, 2011. 


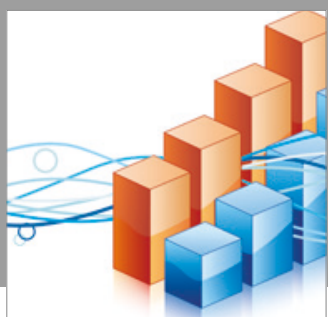

Advances in

Operations Research

vatersals

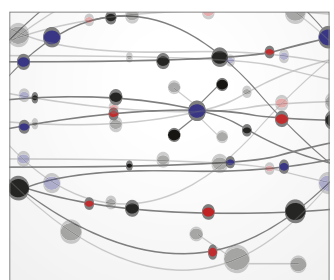

\section{The Scientific} World Journal
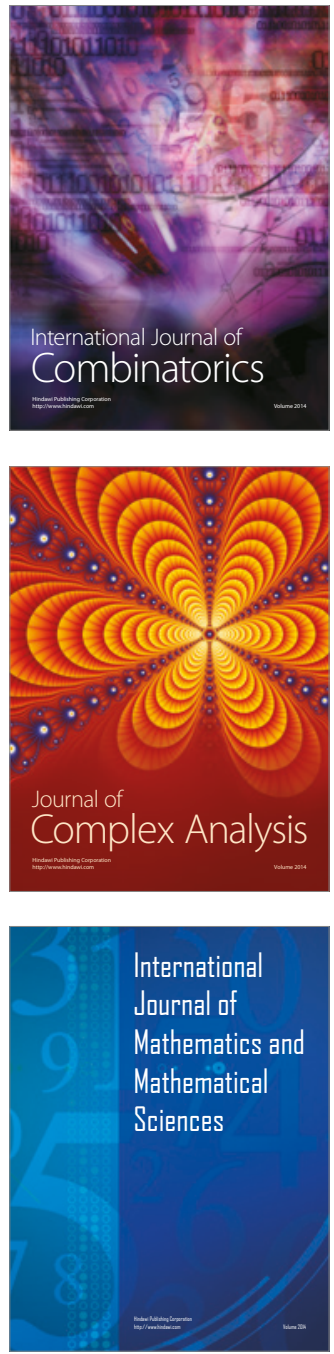
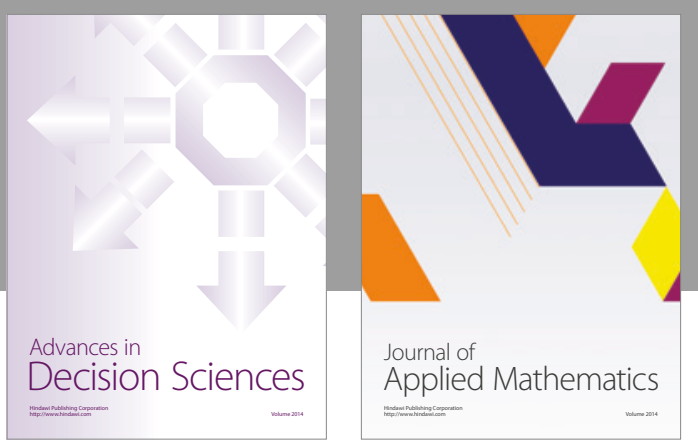

Algebra

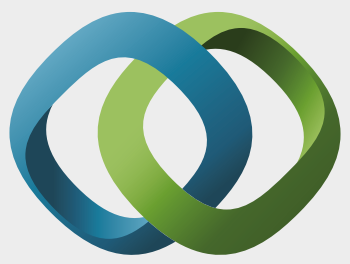

\section{Hindawi}

Submit your manuscripts at

https://www.hindawi.com
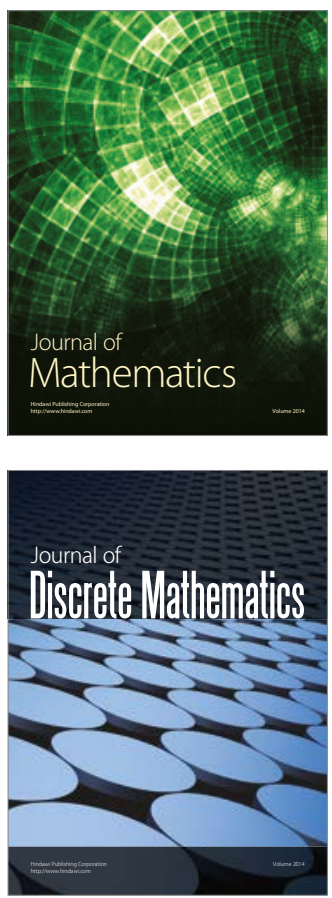

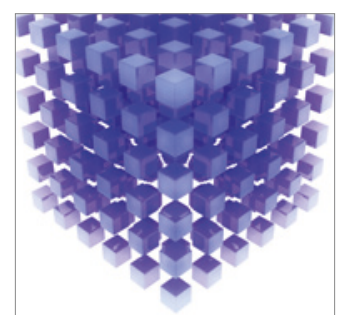

Mathematical Problems in Engineering
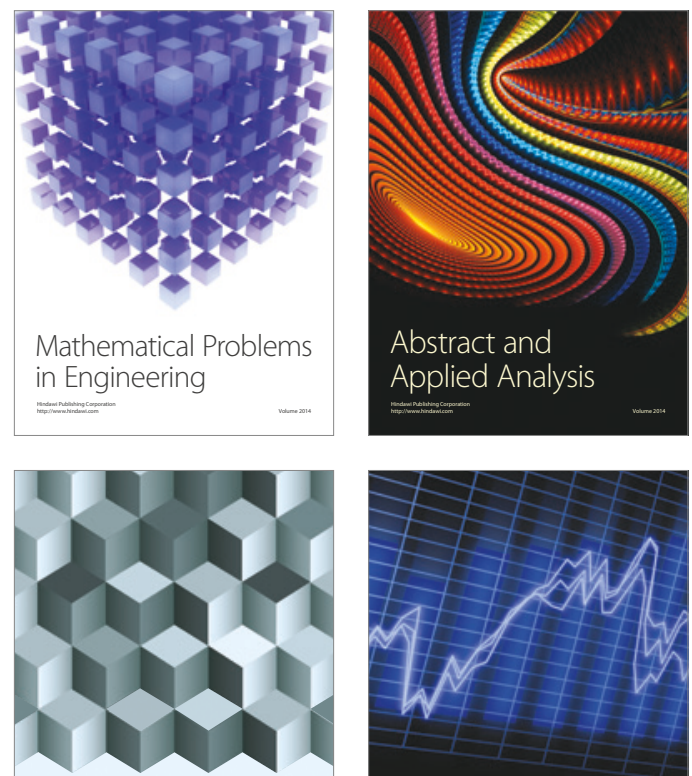

Journal of

Function Spaces

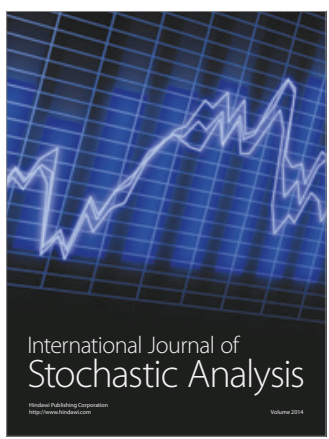

Probability and Statistics
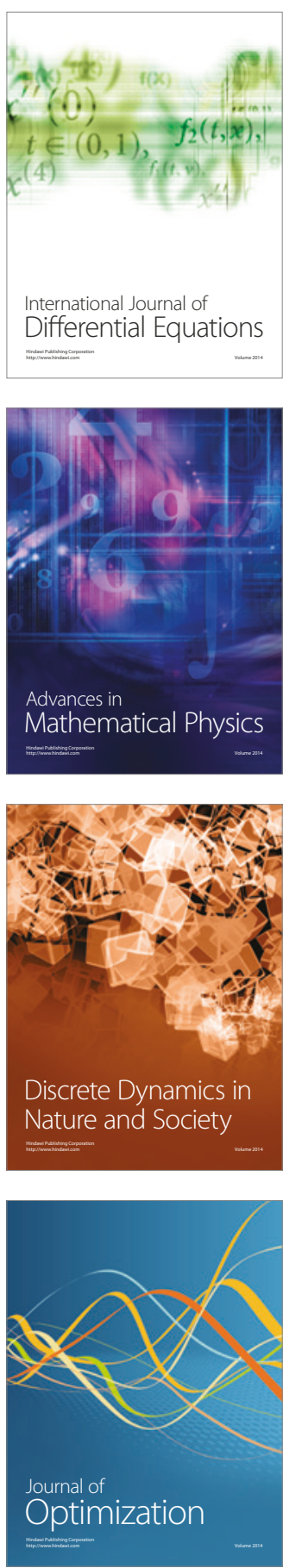